\title{
A Study on the Connotation and its Understanding of College Students' Responsibility Identity
}

\author{
Min CHEN \\ School of Marxism \\ Zhejiang University \\ Hangzhou, Zhejiang, China \\ cmcm@zju.edu.cn
}

\begin{abstract}
The core purpose of responsibility education for college students is the cultivation of responsibility identity. The responsibility identity of college students has rich connotations, and a comprehensive grasp of the connotation is the premise of responsibility education for college students. College students' responsibility identity is a complete psychological process, as well as a process of subjectivity and objectivity unification. The process of college students' responsibility identity conforms to the general law of identity, and its connotation can be grasped from dimensions including the premise of identity, the kernel mechanism of identity, and the essence of identity.
\end{abstract}

Keywords-College students; Responsibility identity; Connotation

\section{INTRODUCTION}

The responsibility education is the key of college moral education, and the cultivation of responsibility identity is the core purpose of the responsibility education. College students' social responsibility identity is directly related to whether they can initiatively take responsibility and consciously fulfill their responsibilities. Fully grasping the connotation of college students' responsibility identity is the prerequisite of carrying out the responsibility education for college students. At present, the study on college students' responsibility education mainly focuses on the cultivation of college students' awareness of responsibility, while no study was conducted from the perspective of identity. Therefore, the research on college students' responsibility identity not only enriches the theory of social identity, but also has important practical significance.

\section{The ConNotation of College STUDENTS' RESPONSIBILITY IDENTITY}

College students' responsibility identity is a process that the college students, as the subject of identity, firstly make psychological acceptance and value selection on the basis of understanding and recognizing their responsibilities, and then voluntarily and consciously accept their own social responsibilities, and initiatively transform it into their longterm and stable intrinsic qualities such as understanding, emotion, will, and ability, and finally taking it as a guideline on their behavior and practice. The essence of college students' responsibility identity is their independent choice of the responsibility ideas, which is a complex spiritual and practical activity. We can further understand the connotation from the following two aspects.

Firstly, responsibility identity is an emotional and ideological acceptance as well as a complete psychological process.

Responsibility identity is a complete psychological process consisting of factors including responsibility identity, responsibility emotion, and responsibility behavior, which are relatively independent but connected with and constrained by each other at the same time. It is also a process involving strong consciousness that college students perceive, judge, recognize, obey, and participate social responsibility, which embodies college students' attitudes and emotions.

From the perspective of psychological structure, at the cognitive level, responsibility identity is college students' perception, understanding, and judgment of factors and system of their own social responsibility; at the emotional level, responsibility identity is college students' irrational evaluation of their own social responsibility, which is also a kind of inner experience and emotional tendency. From the perspective of behavioral intention, responsibility identity is the psychological process that college students consciously adjust their own responsibility behavior in line with the target requirements, continuously overcome difficulties and achieve intended goals in accordance with the social norms and requirements, which embodies individual will.

Secondly, responsibility identity is a process of objectivity and subjectivity unification.

The objectivity of responsibility identity means the existence and the content of responsibility is objective and cannot be changed with individual will. The emergence of responsibility is neither an individual's delusion nor a God's will; instead it is a necessity for the existence and development of human society. Members involving in social relations can never shake off their social responsibilities which are objective and inescapable. On the other hand, responsibility, as an objective rule, is a reflection of social development and time characteristics in social life and is the result of the development and evolution of human society. What's more, the responsibility identity of social members cannot go ahead of their social and historical stages, which is also the embodiment of the objectivity of the responsibilities. 
The subjectivity of responsibility identity is closely linked with individual initiative practice. As the subject of identity, an individual is not only the participant and recipient of social relations, but also the creator and improver of social relations. Therefore, although the existence and content of responsibility are objective, the perceptual understanding and rational identity of responsibility, as well as the selection of responsibility all demonstrate subjective initiative. Similarly, in the process of responsibility identity, college students are not passive recipients, instead, they can take advantage of their subjective initiative to insert counteractive influence on the social system.

\section{Understanding ThreE CONNOTATION Dimensions OF COLLEGE STUDENTS' RESPONSIBILITY IDENTITY}

\section{A. Prerequisites for college students' responsibility identity: role identity.}

Responsibility and role accompany and produce each other; responsibilities are attached to roles while roles carry responsibilities. The role is the identity of a person of certain social status, in certain times, and with certain social relations, whose essence is social role. [1] The social role is the demonstration of various social attributes or social relations of an individual, and it lays the foundation of social groups or social organizations. Different roles are to some extent related with the interests of individuals themselves, others, collectives and even the country, and all roles are inevitably endowed with corresponding role responsibility. College students also play all kinds of roles all the time and the roles are the identity markers of college students in complex social relations. Any rights or obligations that they expect are also attached to one or more of their roles. When a college student chooses a role, it means that he willingly chooses the responsibilities of the role.

“Only by establishing one's roles in society can one be accepted by society. In the existence of society, I can only feel the existence of ' $\mathrm{I}$ ' in the mapping of others and thus determine my behavior." [2] It is impossible for college students to set a role beyond their social relations. Even if they set such a role, the role and identity will become insignificant without the recognition from society. In this sense, role identity can be defined as the heartfelt confirmation of a particular social relation. College student's role identity can be regarded as a process that college students acknowledge the role norms, set correct role in the interactions among individuals and groups or between individual and group, have full recognition and selfawareness of the social roles they play, and achieve the integration of self-perception, self-reference, and self-definition.

Role identity is the premise of role responsibility identity, as well as the beginning of role behavior i.e. the performance of role responsibility. All the effective performance of role responsibilities and the generation of the responsibility ability of the college students are inseparable from the effective identity of their corresponding roles; only if they have comparatively high degree of identity with their roles, they will generate corresponding responsibility identity according to their qualifications and abilities. The higher the identity degree is, the greater the incentive for them to fulfill the corresponding role responsibilities, otherwise, the commitment of the role responsibilities will become hollow words. Therefore, college students should be guided to recognize and accept their role, especially their irrevocable role, which is also the sincere confirmation of their own social relations. The awakening of role consciousness and high role identity of college students will promote them to fully display their talents and creatively play each role, and they will also have a positive responsibility identity, which will enable their responsibility ability and individual virtues to be generated and manifested.

\section{B. The essence of college students' responsibility identity: value identity.}

The identity is in essence the value identity, and it is the reorientation and evaluation of the sense of existence. [3] Value identity is the fundamental force with which a society unites its members. The value identity ultimately allows people to find common meaning and form a value consensus. Value consensus plays a normative, driving, and guiding role in people's ideology, value orientation, and practice behavior.

College students' responsibility identity is a process that college students constantly change their own value structure in order to adapt to socialist dominant value norms, which reflects college students' attitude that they consciously accept and observe the socialist dominant value norms, value standard of selection and value principles. It can also be defined as a process that the college students, as the subject of values, realigning or reorienting their values or values structure through dynamic value relations. This process is on the one hand the process of social value guidance, value transformation and value integration, and on the other hand the process of value judgment, value selection and value practice of college students.

The responsibility identity of college students substantially demonstrates their selection of values and reach of value consensus. The values of college students are the systematic reflection of college students' understanding on value relations, value creation activities, value objects and their significance, as well as the resulting value orientation and psychological orientation. It is the internal driving force for college students' action. The responsibility identity of contemporary college students ultimately reflects the identity of mainstream values of the society-core socialist values. College students guide their own responsible behaviors and practices under the leading values and strengthen and improve their identity of leading values through practices. The process of college students' responsibility identity is the organic unity of personal value and social value with mutual penetration and mutual influence of values and value selection standards.

\section{The core mechanism of college students' responsibility identity: moral internalization.}

The concept of internalization was first proposed by the French sociologist Duke Haim, referring to the transformation of social consciousness to individual consciousness, which is a developmental process from "discipline" to "autonomy". Ethical internalization is a subliming process that individuals transform social morality to their internal behavioral norms and value goals, form corresponding moral qualities and conduct conscious moral behaviors and practice with external education, 
indoctrination, demonstration, and guidance as well as individual learning, selection and identity. [4] Therefore, moral internalization is a special form of internalization. It is a process that the moral subject, through self-education and practice, internalize the external moral principles into their own value orientation and behavior, and imperceptibly strengthen their sense of mission and sense of responsibility. Moral internalization is not merely turning the external moral norms into internal understandings, but also internalizing into beliefs and then externalizing into actions and finally forming individual moral quality and moral personality.

Moral internalization plays a dominant role in the formation and development of individual morality, and it is also the core mechanism for the generation of college students' responsibility identity. As identity is not only the process that the identity subject acts on the identity object, but also the process that the identity objects acts to the identity subject. "Although identity can arise from dominant institutions, it can only be real when social actors internalize it and build its meaning centering the process of internalization.” [5] Thus, identity does not exist naturally but constructed through the internalization of the subject. Only if the external demands internalized as inner beliefs, can identity become sustained and stable. The same applies to the responsibility identity of college students. The process of moral internalization is the process of transforming social morality into individual morality. It is through the mechanism of moral internalization that college students can transform social responsibility norms and responsibilities requirements into their own moral demands, form internal forces that administrate and control their responsibility behaviors, and ultimately take it as a guide to their own behavior and practice.

\section{SUMMARY}

College students' responsibility identity has rich connotations and inherent logic and characteristics. In the implementation of college students' responsibility education, we must fully grasp the above-mentioned connotations, give full play to the subjectivity of college students, so as to achieve a high degree of identity of social responsibility among college students, and promote their realization of life values in vivid social practices.

\section{REFERENCES}

[1] R. Lin, "Role responsibility, role morals and responsibility education for college students," Educational Journal Monthly, vol. 8, pp.27-29, August 2011. (In Chinese).

[2] H. Li, Image and Existence. Shanghai: Shanghai Bookstore Press, 2011, pp.333. (In Chinese).

[3] Y. Jia, "The philosophical connotation of identity and the essence of value identity," Journal of Shandong Normal University (Humanities and Social Sciences), vol. 1, pp.10-16, September 2006.(In Chinese).

[4] J. Long, "On the subjective and objective conditions of moral internalization," Guide of Ideological and Theoretical Education, vol. 6, pp.52-56, August 2009.(In Chinese)

[5] M. Castell, The Power of Identity, Translated by R. Cao, Beijing: Social Sciences Academic Press, 2006, pp.5. (In Chinese). 